\title{
Spinal cord infarction occurring during thoraco-lumbar sympathectomy
}

\author{
J. TREVOR HUGHES AND ALEX G. MACINTYRE ${ }^{1}$
}

From the Radcliffe Infirmary, Oxford

\begin{abstract}
The arterial blood supply of the spinal cord depends on a single anterior spinal artery and two posterior spinal arteries. The anterior spinal artery, which is the more important, commences within the cranial cavity by the union of the anterior spinal branches of each vertebral artery and subsequently is fed by several tributary arteries. Down the length of the spinal cord the anterior spinal artery receives paired tributaries accompanying each anterior nerve root, and, arising from the vertebrals, the ascending cervical branches of the inferior thyroid, the costocervical trunk, the costal, lumbar, iliolumbar, and lateral sacral arteries. Most of these arterial tributaries are small and the blood supply is largely dependent on four to 10 of these arterial tributaries which are especially large. Their position and size are variable, but at least one joins the cervical cord, two the thoracic cord, and one the lumbar cord. The largest thoracic tributary has been given the name, the great ventral radicular artery.
\end{abstract}

Spinal cord infarction, because of interference with an important radicular tributary, is a rare complication of thoraco-lumbar sympathectomy. In a brief survey of the literature we found only 12 previously recorded cases in which this complication was presumed to have occurred. Rubio (1953, quoted by Corbin, 1961) reported three cases, and a further case was added by Mosberg, Voris, and Duffy (1954) who also cited four cases of Bassett (1948) and a personal communication of three cases of Poppen. Nathan (1956) mentions a further case. Detailed pathological observations at necropsy were made in two cases, that of Mosberg and that of Nathan. The following case report with necropsy findings describes spinal cord infarction occurring as a complication of the operation of thoracolumbar sympathectomy.

\section{CASE REPORT}

In 1947, at the age of 31, Miss V. G. (Radcliffe Infirmary no. 300290), a bank clerk, developed malignant hypertension. In 1950 her blood pressure recordings ranged

'Present address: Walton Hospital, Liverpool 9. from $240 / 130$ to $260 / 150 \mathrm{~mm}$. $\mathrm{Hg}$ and she entered a London hospital for thoraco-lumbar sympathectomy. The left sympathetic chain, from T2 to L2 plus the splanchnic nerves, was extirpated at the uneventful first stage. Three months later the right sympathetic chain, from $\mathrm{T} 1$ to $\mathrm{L} 2$ plus the splanchnic nerves, was removed through a thoracotomy with ninth rib resection. There were no obvious technical problems or hypotensive episodes. On recovery from the general anaesthesia, an incomplete sensori-motor loss below T9 was immediately apparent. Lumbar puncture revealed entirely negative findings.

Subsequently the paresis and sensory loss partiallyo recovered, but on discharge four months later she was only able to walk a few yards with a stick and a right le 8 calliper. Both legs remained spastic and without perबि ception of pain, temperature, and vibration, but some perception of touch and joint movement returned. During the next 10 years the neurological picture remained ung changed but the blood pressure slowly increased. The final admission was the result of a fatal subarachnoi haemorrhage.

\section{NECROPSY FINDINGS}

The general findings (P.M. 974/60) were left ventricular hypertrophy, fibrous pleural adhesions, and shrunken kidneys (right more than left). Sections showed changes of hypertension with evidence of prior chronic pyelonephritis.

BRAIN The rupture of a congenital berry aneurysm on the left anterior cerebral artery had caused such extensive subarachnoid bleeding as to be the immediate cause of death.

MENINGES The subarachnoid space was filled with recent blood clot.

VESSELS The anterior spinal artery was joined by large radicular arteries accompanying the left $\mathrm{C3}$, right $\mathrm{C} 8$, left $\mathrm{T} 1$, and left $\mathrm{L} 2$ anterior nerve roots. The left L2 branch was especially large and above this there was no major tributary to the anterior spinal artery until that accompanying the left $\mathrm{T} 1$ anterior nerve root. The veins appeared prominent, 


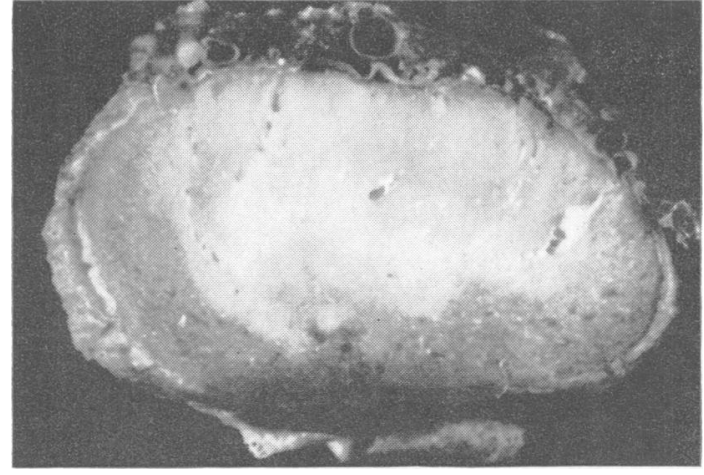

FIG. 1. Transverse cut through the lower thoracic region of the spinal cord viewed from above. The atrophied anterior part of the cord is grey.

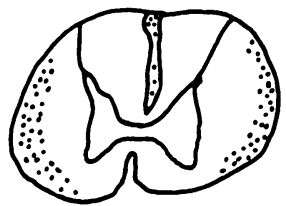

T2
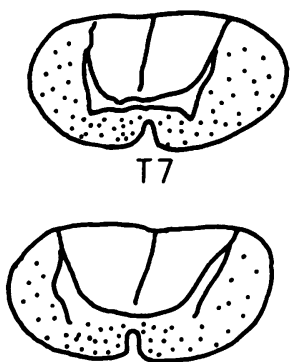

T9

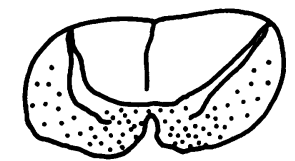

TII

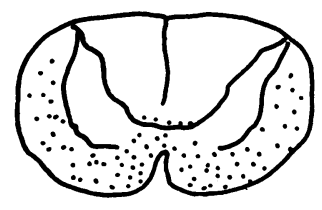

LI

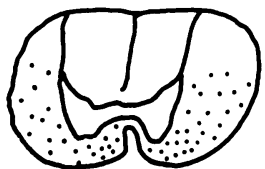

T6.
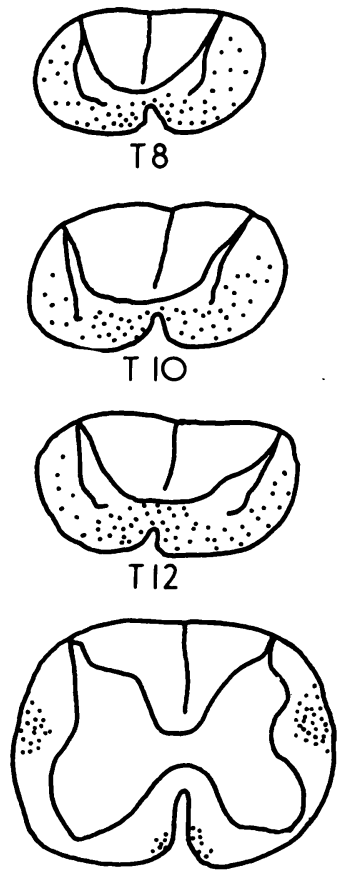

L4

FIG. 2. Drawings from camera lucida tracings of transverse sections through the spinal cord at various segmental levels. The stippled area is gliotic. Note the destruction of the anterior horn and shrinkage of the anterior two-thirds of the cord from T6 to L1. Wallerian degeneration is seen in T2 (above) and L4 (below) the cord lesion.

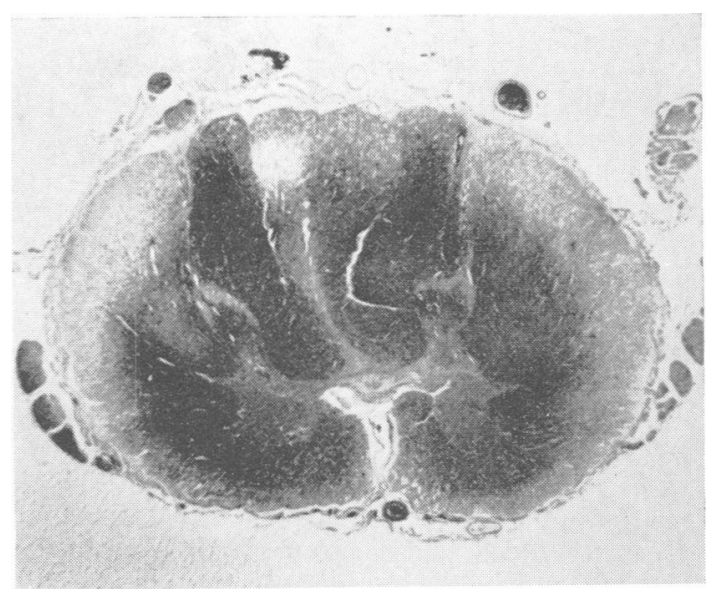

FIG. 3

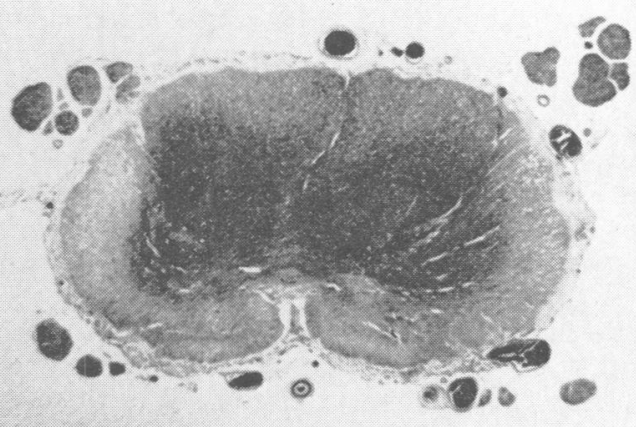

FIG. 4

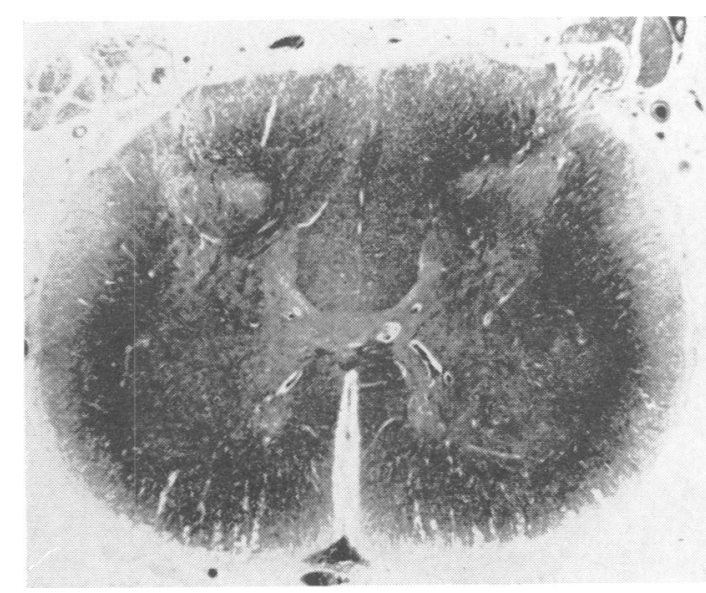

FIG. 5

FIGS. 3, 4, AND 5. Myelin stain of transverse sections through T3, T10, and L4. In T10 there is atrophy of the anterior two-thirds of the cord. Wallerian degeneration is seen in T3 and L4. 
particularly on the anterior aspect of the spinal cord.

SPINAL CORD From T6 to L1 the spinal cord was shrunken, the anterior part of the cord being particularly affected (Fig. 1).

\section{HISTOLOGICAL EXAMINATION OF THE SPINAL CORD}

Transverse sections were taken through C5, C8, T1-T12, L1-L5, and S2.

The sections C5, C8, and T1-T4 showed similar appearances (Fig. 3). There was leptomeningeal thickening with some recent subarachnoid blood. Myelin and fibres were lost in the posterior columns and in the anterior and posterior spino-cerebellar tracts due to upward Wallerian degeneration above the cord lesion. At these levels the anterior horns showed no neuronal depletion and the nerve roots were normal. The vessels showed no evidence of occlusion. A transverse section through T5 showed the upper limit of spinal cord damage. The anterior horns of this segment showed few neurones which were intermingled with some astrocytic gliosis. The main damage to the spinal cord was from T6 to T12 (Figs. 2 and 4). These segments showed severe depletion or absence of neurones from the anterior horns. The anterior and lateral columns were shrunken, the normal tissue being replaced by dense astrocytic gliosis. All the anterior nerve roots from these segments showed atrophy with myelin and fibre loss. There was considerable leptomeningeal thickening. None of the vessels seen showed any evidence of occlusion. The lower limit of the cord lesion was seen in L1 where the anterior horn showed depletion of neurones with gliosis. Sections of L2, L3, L4 (Fig. 5) and L5, and of S2 showed pyramidal tract degeneration with myelin and fibre loss due to downward Wallerian degeneration.

\section{DISCUSSION}

In the case described here the region of spinal cord infarction is the anterior spinal artery territory from $\mathrm{T} 7$ to $\mathrm{T} 12$ cord segments, with minor changes in T6 and L1. This infarcted region corresponds to the distribution of a major thoracic tributary to the anterior spinal artery. The vessel obstructed in all probability entered from the right side, being disturbed during the second operation of right thoraco-lumbar sympathectomy. The vessel concerned may have been damaged during the rib resection, an operation known to be the occasional cause of spinal cord ischaemic damage. Rouquès and Passelecq (1957) reported a case of the Brown-
Séquard syndrome following thoracoplasty, and $\bar{Z}$ Binet (quoted by Corbin, 1961) observed paraplegia following a left pneumonectomy. Alternatively during the actual extirpation of the sympathetic chain a nearby intercostal artery may have bled and so required surgical ligation.

The rarity of this complication of sympathectomy requires consideration. The operation is a common one and accidental damage to intercostal or other arteries occasionally occurs, usually without untoward sequelae. The explanation lies in the peculiar anatomical arrangement of the vascular supply of the spinal cord whereby only a few of the numerous tributaries to the anterior spinal artery are of profound importance. When by chance the artery obstructed gives origin to a major radical like the great ventral radicular artery, extensive ischaemia will occur.

The injection experiments of Bolton (1939) have suggested that the blood flow in the anterior spinal artery is in a downward direction. When an important tributary artery is injected the whole of the anterior spinal artery down to the filum terminale is filled, but the injection material only passes up= wards for one or two segments. An anatomica $\Phi$ reason for this is that a large tributary artery usuall joins the anterior spinal artery in a caudal directio and for a short distance above this junction the calibre of the anterior spinal artery is small, whereas immediately below the junction the calibre increases In individual cord segments, Bolton could find little evidence of anastomosis between anterior spind and posterior spinal arteries. He did find at the caudal end of the spinal cord an extensive anastomosis between the anterior spinal artery and both posterior spinal arteries.

In the case described here the extent of the spinal cord infarction agrees with the anatomical studies of Bolton. Caudal to the infarcted spinal cord, the first large tributary accompanied the L2 nerve root. This large vessel had provided for the lumbo-sacral cord but had failed to nourish the thoracic cord above. This finding confirms the caudal direction of blood flow in the anterior spinal artery. The lack of demonstrable anastomosis between anterior and posterior spinal arteries in an individual cord segment was also confirmed since the infarcted region was strictly confined to the anterior two-thirds of the spinal cord.

\section{SUMMARY}

A case of spinal cord infarction occurring during thoraco-lumbar sympathectomy is described.

The affected region of the spinal cord (the anterior two-thirds of segment T6-T12) indicated that a 
major tributary to the thoracic cord had been obstructed.

The case illustrates anatomical peculiarities of the arterial supply to the spinal cord.

We are grateful to Mr. J. Pennybacker for permission to publish this case and to Dr. D. Oppenheimer who performed the necropsy.
REFERENCES

Bassett, R. C. (1948). Med. Clin. N. Amer., 32, 187.

Bolton, B. (1939). J. Neurol. Psychiat., 2, 137.

Corbin, J. L. (1961). Anatomie et Pathologie Artérielles de la Moelle. Masson, Paris.

Mosberg, W. H., Voris, H. C., and Duffy, J. (1954). Ann. Surg., 139 330.

Nathan. P. N. (1956). J. Neurol. Neurosurg. Psychiat., 19, 88.

Rouquès, L., and Passelecq, A. (1957). Revo. neurol., 97, 146.

\section{The August 1963 Issue}

\section{THE AUGUST 1963 ISSUE CONTAINS THE FOLLOWING PAPERS:-}

A new approach to unilateral and bilateral lobotomies for psychomotor epilepsy ERIC TURNER

Seizures induced by movement: report of a case relieved by operation M. A. FALCONER, M. V. DRIVER, and E. A. SERAFETINIDES

The relationship between generalized paroxysmal E.E.G. discharges and various test situations in two epileptic patients BARBARA TIZARD and J. $\mathbf{H}$. MARGERISON

Pathological plantar response: disturbances of the normal integration of flexor and extensor reflex components LENNART GRIMBY

Myopathic changes in a muscular dystrophy carrier VICTOR DUBOWITZ

The incidence of ringed fibres and sarcoplasmic masses in normal and diseased muscle JAAP BETHLEM and GEORGE K. VAN WIJNGAARDEN

The localization of alkaline phosphatase activity in cerebral blood vessels R. G. BANNISTER and F. C. A. ROMANUL
The effect of metabolic acidosis and alkalosis on the blood flow through the cerebral cortex A. MURRAY HARPER and RUTH A. BELL

Trigeminal root and ganglion injections using phenol in glycerine for the relief of trigeminal neuralgia ANTONY JEFFERSON

Results of antero-lateral cordotomy for pain in cancer P. W. NATHAN

A fatal case of cerebral abscess due to Nocardia asteroides S. I. JACOBS and R. MYLES GIBSON

Epidemiology of multiple sclerosis in the counties of Northumberland and Durham DAVID C. POSKANZER, KURT SCHAPIRA, and HENRY MILLER

Studies in the development and breakdown of the use of names III Recovery from nominal dysphasia GERARD ROCHFORD and MOYRA WILLIAMS

Book reviews

Copies are still available and may be obtained from the PUBLISHING MANAGER, BRITISH MEDICAL ASSOCIATION, TAVISTOCK SQUARE, W.C.I., price 18s. 6D. 